\title{
Where are the Endocrinologists?
}

\author{
Chloe Broughton, Shaza Ahmed, Beas Bhattacharya, Great Western Hospital, Swindon
}

\section{Introduction}

Hyponatraemia is defined as serum sodium concentration $<135 \mathrm{mmol} / \mathrm{L}$. It is the most common electrolyte disorder encountered in clinical practise ${ }^{1}$. It is associated with an increase in mortality and length of stay, independent of diagnosis and clinical variables ${ }^{2}$. Despite this it is often inadequately investigated and poorly managed ${ }^{3}$. As a number of endocrine conditions can cause hyponatraemia, endocrinologists often have the necessary clinical skills and

\section{Methods}

A retrospective audit was performed of patients admitted to The Great Western Hospital (GWH) serum sodium of $127 \mathrm{mmol} / \mathrm{L}$ or less on admission, over a three month period. The aims were to evaluate how hyponatraemia is investigated and whether specialist input from the endocrinology team improves the management of these patients.

\section{Results}

In the Audit:-

75 patients were included in the audit; 27 male (36\%) and 48 female $(64 \%)$.

Serum sodium of $127 \mathrm{mmol} / \mathrm{L}$ or less on admission.

8 investigations were identified as essential when investigating patients with Hyponatraemia-only $4 \%$ of patients had all 8 investigations completed.

Less than $27 \%$ of patients had a urine sodium, urine osmolality and serum osmolality requested during admission.

\section{Only 7 patients $(9 \%)$ were either referred to the endocrinology} team or were reviewed by the endocrinology team during admission.

These patients had an average of 6.9 out of 8 of the essential investigations, whereas those patients not reviewed by

\section{Discussion}

This audit confirms that:

-Hyponatraemia is often not recognised, inadequately investigated and poorly managed.

-Results suggest that an endocrine opinion is rarely requested -When reviewed by an Endocrinologist patients are more likely to have appropriate investigations requested

-When referred to specialist and correctly investigated, increases correct diagnosis and appropriate management.

\section{Hyponatraemia Audit 2014}

Essential Investigations:

* Urinary sodium

Urinary osmolality

Serum osmolality

Random blood glucose

Total protein

Lipids

Serum cortisol

TSH

\section{Hyponatraemia Audit 2014}

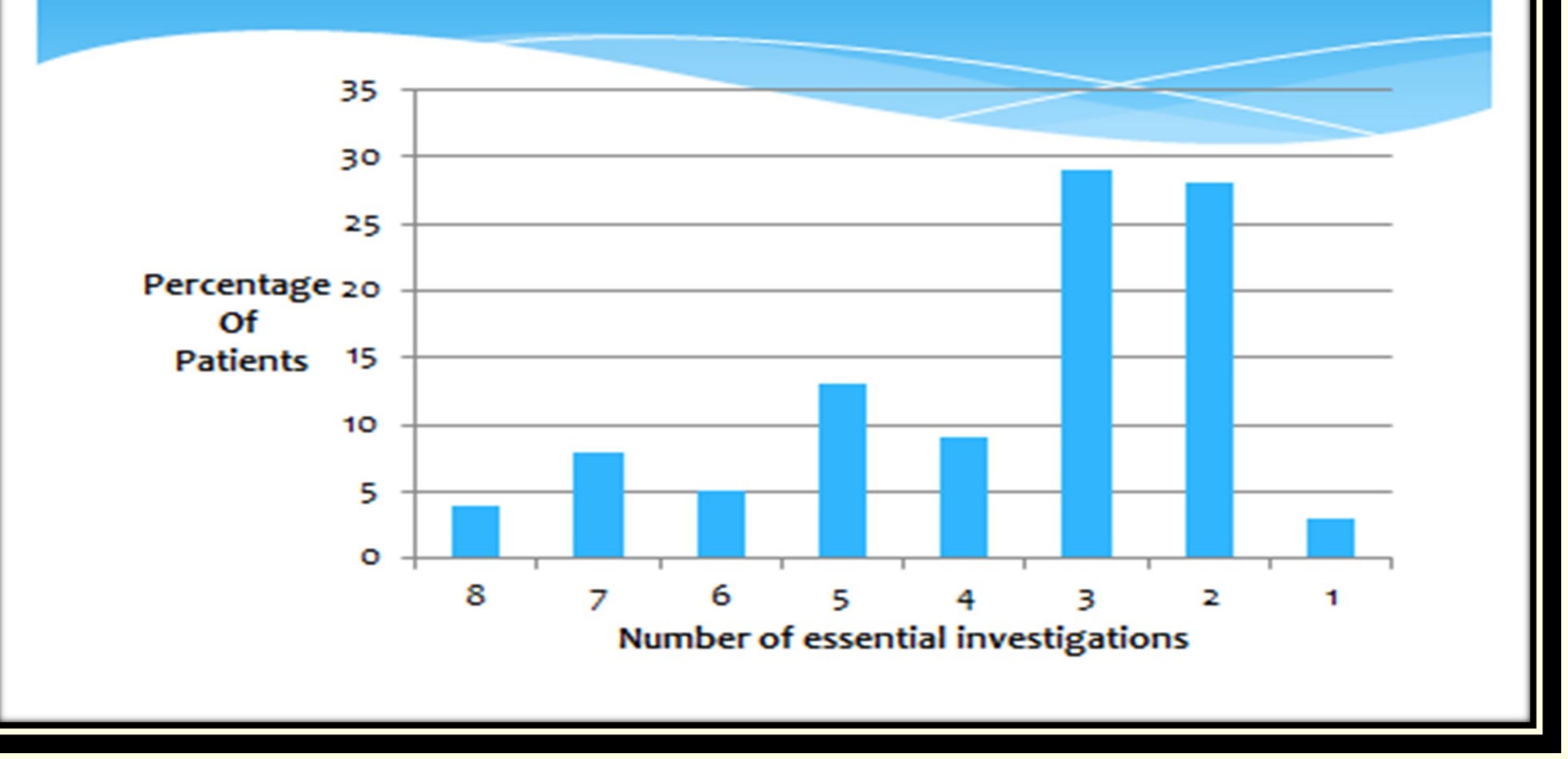

\section{Hyponatraemia Audit 2014}

Specialist Input

* Only 7 patients (9\%) were either referred to or reviewed by the endocrinology team

during admission

Endocrine input: 6.9 out of 8 investigations GIM input: 3.4 out of 8 investigations

1. Spasovski, G et al. Hyponatraemia guidelines development group Clinical practise guideline on diagnosis and treatment of hyponatraemia. Eur J Endocrinol 2014;170(3):G1-47.

2. Ballin, $L$ et al. Hyponatraemia at hospital admission is a predictor of overall mortality. Intern Med J 2015;45(2):195-202.

3. Ploutarchous, T and Bouloux, PM. Inpatient hyponatraemia: adequacy of investigation and prevalence of endocrine causes. Clinical Medicine 2015; 15:20-24. 